\title{
Comparative study on the effect of cadmium and hydrocortisone treatment on the brain of rats experimentally infected with Toxoplasma gondii
}

\author{
K.H. Al-Mallah ${ }^{1}\left(\right.$, S.S. Aghwan ${ }^{\circledR}$ and Q.T. Al-Obaidi ${ }^{\circledR}$ \\ ${ }^{1}$ Department of Pathology and Poultry Diseases, ${ }^{2}$ Department of Microbiology, ${ }^{3}$ Department of Preventive Medicine, \\ College of Veterinary Medicine, University of Mosul, Mosul, Iraq
}

\begin{tabular}{l} 
Article information \\
\hline Article history: \\
Received September 22, 2020 \\
Accepted January 23, 2021 \\
Available online October 1, 2021 \\
\hline Keywords: \\
Toxoplasma gondii \\
Cadmium chloride \\
Hydrocortisone \\
Rats \\
\\
\hline Correspondence: \\
K.H. Al-Mallah \\
karamyahya74@uomosul.edu.iq
\end{tabular}

\begin{abstract}
This study was dedicated to detecting the effects of cadmium chloride and of cortisone on experimental infection with Toxoplasma gondii in rats through studying brain tissue. Twenty-four adult albino male rats were used, divided into four groups, comprising: untreated control as group 1, group 2: infected with intraperitoneal injection of Toxoplasma gondii 80 tissue cysts per animal, group 3: infected with Toxoplasma gondii and treated with intraperitoneal injection of cadmium chloride $1.5 \mathrm{mg} / \mathrm{kg}$ once a week, group 4: infected with Toxoplasma gondii and treated with intramuscular injection of hydrocortisone in a dose $0.5 \mathrm{mg} / \mathrm{kg}$ once a week. After 30 days of treatment for all groups, the animals were sacrificed, and the gross and histopathological examinations were performed on the brains of the rats. The results revealed the presence of changes in the infected groups including appearance of toxoplasma tissue cysts in the grey matter, with mild to moderate perineuronal and periaxonal edema. There were further changes observed in infected groups which treated with cadmium chloride including perineuronal satelletosis, perineuronal edema and demyelination in neuronal axons, otherwise the infected groups treated with cortisone did not show any noticeable difference from the group of infection only. It is concluded that cadmium increase the intensity of occurrence of lesions induced by Toxoplasma gondii in the brain tissue of the rats, considering that all noticeable lesions ranged from mild to moderate in severity, and the differences between groups may be related to the nature of the pathogen used.
\end{abstract}

DOI: 10.33899/ijvs.2021.128436.1575, (CAuthors, 2021, College of Veterinary Medicine, University of Mosul.

This is an open access article under the CC BY 4.0 license (http://creativecommons.org/licenses/by/4.0/).

\section{Introduction}

Toxoplasmosis is zoonotic parasitic disease $(1,2)$ can be considered as one of the most universally distributed infectious diseases (3). The infection is caused by Toxoplasma gondii, which is a protozoal parasite from the order: Sporozoasida, family: Sarcocystiidae, genus: Toxoplasma (4). This parasite can invade several mammalian tissues $(5,6)$, as well as avian tissues like in local poultry industry (7) Toxoplasma tissue cysts can develop in lungs, liver and kidneys but is most commonly noticed in nervous and muscular tissues, including brain, eyes, skeletal muscles, and heart $(8,9)$. The lesions induced by Toxoplasma infection are typically accompanied by inflammatory response, especially the necrosis in the infected tissues generating clinical signs such as anemia, headache, fever, and muscle pain as well as long-term complications resulting from specific cells destruction in brain, eyes, lungs and heart (10). The cadmium is one of the heavy metals of industrial importance, but it is also a dangerous pollutant in environment which the exposure to it leading to certain toxic effects to many tissues, especially the brain $(11,12)$. The serious toxic effect of cadmium on plants and animals is caused by its ability to inactivate the intramembranous ionic 
exchange, thus affecting their permeability (13), and as a result cadmium has a direct harmful effect on the liver and kidneys and may result in acute renal failure (14), It is also reported that cadmium chloride consumption affects the endocrine functions with adverse impact on the histological view of each thyroid and adrenal glands of rats (15). The cortisone drugs are glucocorticoids, which are steroidal compounds with a hormonal effect used clinically to suppress inflammations and exaggerated immune responses by stopping the release of inflammatory mediators (16). The goal of the study is to compare the pattern of Toxoplasma infection in the brain of rats, alone, and in combination with cadmium chloride exposure and under effect of cortisone drug to monitor the effects through histopathological point of view.

\section{Materials and methods}

\section{Animals and housing}

Twenty-four adult albino male rats aged from 2.5 to 3 months and weighing between $200-250 \mathrm{gm}$, were used in this experiment. They were obtained from the animal house of the college of Veterinary Medicine after receiving the approval of the Ethical Committee for the experiment. The animals were kept in standard plastic cages of $12 * 25 * 10 \mathrm{~cm}$, with steel buckle cover, and were freely supplied with food and water and housed within $22 \pm 25^{\circ} \mathrm{C}$ and $12-12$ light-dark cycle. Those animals were randomly distributed between four groups with six animals for each group.

\section{The isolation of Toxoplasma gondii}

Toxoplasma gondii was diagnosed by examining the impression smears made from placentas of the aborted ewes (17). The positive samples for toxoplasmosis were digested by pepsin as described by (18).

The fluid extracted from infected placenta was inoculated in albino mice intraperitoneally, typical tissue cysts were found in the brain of the inoculated mice who sacrificed and the suspension was made from infected brains by homogenisation and washing with phosphate buffered saline three times, this suspension containing the brain tissue cysts was inoculated in the peritoneal cavity of the rats of experiment.

\section{The experiment and manipulation}

The first group was the control group, which was not subjected to any treatment for 30 days; the second group was infected with 80 Toxoplasma gondii tissue cyst for animal as an infective dose by intraperitoneal injection once, on day one of the experiment.

The third group was infected and treated with cadmium chloride $1.5 \mathrm{mg} / \mathrm{kg}$ by intraperitoneal injection once a week. The fourth group was also infected and treated with hydrocortisone $0.5 \mathrm{mg} / \mathrm{kg}$ once a week for the period of the experiment.

\section{Gross and histopathological examination}

The animals were sacrificed, dissected and the gross pathological changes were recorded; then samples were taken from the brain and directly preserved in $10 \%$ neutral buffered formalin. Trimming was performed followed by dehydration using gradual concentrations of ethyl alcohol, cleared with xylol, embedded with paraffin wax at $57^{\circ} \mathrm{C}$, set in paraffin blocks and sectioned to 4-6 micrometer sections and stained with hematoxylin and eosin (19-21), and examined under light microscope Kruss, Germany and photographed using digital camera, Sony, Japan.

\section{Results}

Histopathological examination revealed the existence of pathological changes in brain tissue at the three treated groups compared with control group. The toxoplasma infected group showed toxoplasma tissue cyst in brain tissue, mostly in the cerebral medulla surrounded by mild microgliosis, perineuronal and periaxonal edema (Figure 1). In the infected and cadmium chloride-treated group, the same lesions mentioned above were observed with perineuronal satelletosis, Hyperaemic arterioles and capillaries, perineuronal edema and mild microglial cells proliferation with increase of degenerative and necrotic neurons surrounded by microglial cells (Figure 2). The infected group with cortisone treatment showed the same lesions as the infected group with noticeable toxoplama tissue cyst and cerebral cortex and medulla with microgliosis, perineuronal and periaxonal edema (Figure 3).

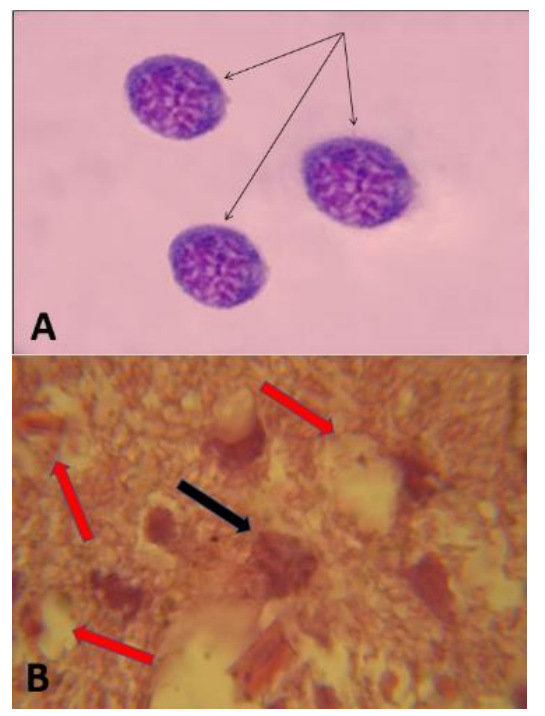

Figure 1: A: Microscopic image of tissue cysts in impression smears of the brain of rat (Black arrows). Giemsa stain, magnification $1000 \mathrm{X}$. B: Section of the brain medulla of the rat from the group infected with Toxoplasma gondii showing Toxoplasma tissue cyst (Black arrow) with mild periaxonal edema (Red arrows). H\&E stain. Magnification 780 X. 


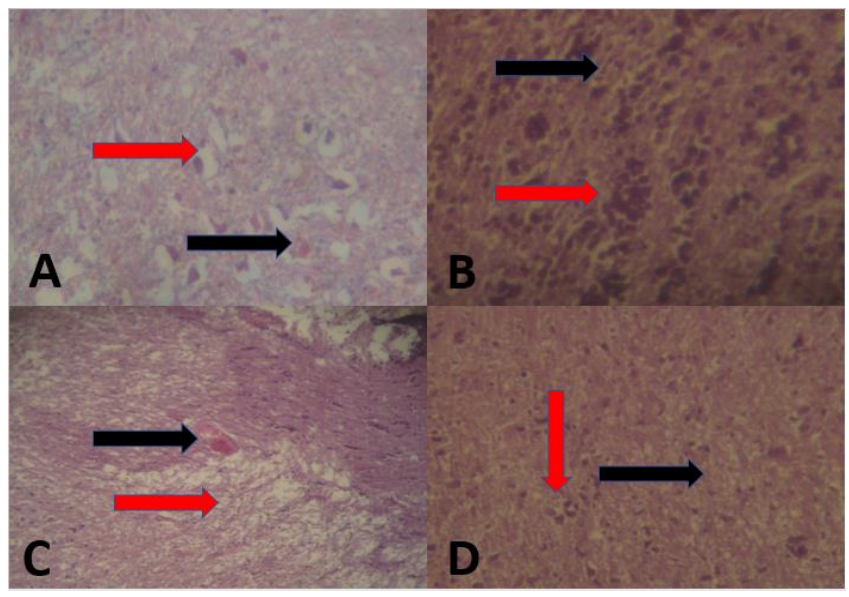

Figure 2: A: Section of brain cortex of rat infected with Toxoplasma gondii and treated with cadmium chloride showing congestion of capillaries (Black arrow) with mild peri axonal edema (Red arrow) Magnification 780 X. B: Section of brain Medulla of rat infected with Toxoplasma gondii and treated with cadmium showing neuronal demyelination (Black arrow) Perineuronal microgliosis (Red arrow). 730 X. C: Section of brain medulla of rat infected with Toxoplasma gondii and treated with cadmium sowing capillary congestion (Black arrow), Perineuronal edema (Red arrow). Magnification 115X. D: Section of brain medulla of rat infected with Toxoplasma gondii and treated with cadmium sowing demyelination and vacuolation in myelin sheaths (Black arrow), microgliosis (Red arrow). Magnification 145 X. Staining H\&E for all images.

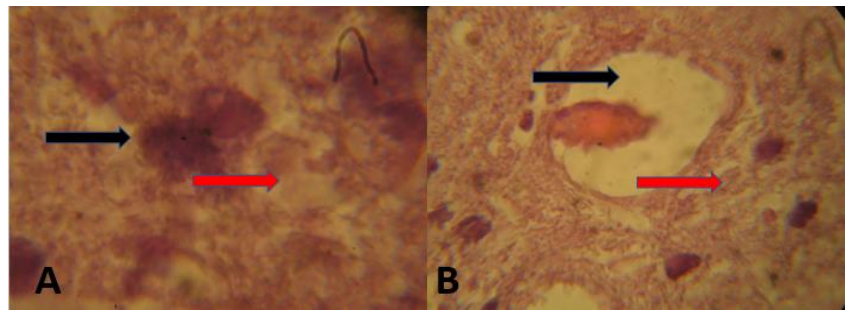

Figure 3: A: Section in brain cortex section of rat infected with Toxoplasma gondii and treated with cortisone showing toxoplasma tissue cyst (Black arrow) with mild peri axonal edema (Red arrow). Magnification 780 X. B: Section of brain medulla of rat infected with Toxoplasma gondii and treated with cortisone showing vasogenic edema (Black arrow) with mild demyelination in myelin sheathes (Red arrow). $730 \mathrm{X}$. Staining H\&E for all images.

\section{Discussion}

The Toxoplasma gondi infected group revealed histopathological changes in brain tissue represented by the presence of tissue cyst at cortex and medulla of cerebrum and medulla oblongata. Similar results were obtained by AlKhalidy et al. (22) in Al-Diwaniyah province/ Iraq, who noticed the calcified Toxoplasma tissue cysts in brain of affected cats. This study also demonstrated pathological changes as mild focal microgliosis, perineuronal and periaxonal edema, agreeing with Al-Saidya and Al-Kennany (23), who recorded these lesions after experimental infection with local isolates of Toxoplasma gondii in local cats and they also reported encephalitis in more advanced stages.

Our results also were supported by the findings of $\mathrm{Al}-$ Khanaq and Jasim (24), who stated that intraperitoneal inoculation of Toxoplasma gondii in albino male rats resulted in the development of perineuronal edema, demyelination, microgliosis. besides, pathological changes were noticed in rats' brains of cadmium-controlled group compared with control, including perineuronal microgliosis and astrocytosis, hyperemic capillaries, and mild to moderate perineuronal and periaxonal edema.

There was also increase in number of apoptotic neurons surrounded by microglial cells, while similar results were reported by Wang and Du (25), who showed that prolonged exposure to cadmium generated accumulative toxic effects in liver, kidneys, central and peripheral nervous systems resulting from precipitation of cadmium and increased permeability of blood brain barriers.

It was stated by Manton and Cook (26) that the mechanism of neurotoxicity with heavy metals is not completely understood but the anatomical and physiological nature of choroid plexus makes it a target for xenobiotics like cadmium and lead that accumulates more intensively than in cerebrospinal fluid or cerebral cortex.

Observations by Kaoud and Mekawy (27) supported the behavioral effects of cadmium reflecting nervous effects as dose-dependence increases in non-social activity and decreases the social activity in rats, including nose to genital, nose to nose contacts and frequency of fighting. Disabled cerebral functions by neurotoxicity were confirmed by histopathological and neurochemical analysis.

Yang and Fan (11) stated that severity of histological changes in brain in cadmium toxicity depends on the dose by noticing more advanced changes at medium and high doses than noticed in low dose of cadmium.

The sever changes were separation of gray matter in cerebral cortex, severe hyperemia, infiltration of eosinophils, vacuolar demyelination and increased number of apoptotic neurons.

The same researchers described ultrastructural changes including polar aggregation of heterogenous chromatin, incomplete or fused nuclear membrane, Perinuclear areas expansion, abnormal folding in mitochondrial membranes and decreased synaptic cleft areas, so they concluded that cadmium causes microscopical and ultrastructural changes in infant mice cerebral cortex.

Similar results were obtained by Afifi and Embaby (28) through giving rats $5 \mathrm{mg} / \mathrm{Kg} \mathrm{B}$.W of cadmium. The cerebral cortex revealed severe degenerative changes in pyramidal and granular cells and ultrastructural changes including rough endoplasmic reticulum and Golgi apparatus 
expansion, mitochondrial swelling and Polar orientation of nuclear chromatin besides demyelination in neuronal axons and vacuolation of neuropil, and they noticed less severe changes when animals were treated with ascorbic acid, giving indication of the protective rule of the antioxidants against cadmium neurotoxicity.

It was stated by Borges et al. (29) that cadmium increases lipid peroxidation and levels of reactive oxygen species in neural plates.

This was supported by Yuan et al. (30) who explained that incidence of neuronal apoptosis was connected to ROS production because of disturbances in calcium metabolism and disruption of mitochondrial membranes activity, resulting in activation of caspas-3, caspas-9, and PARP concluding that apoptosis being activated through mitochondrial -caspase signaling pathway and this may explain the histopathological changes in our study.

\section{Conclusion}

Cadmium intense the occurrence of lesions induced by Toxoplasma gondii in the brain tissue of the rats, considering that all noticeable lesions ranged from mild to moderate in severity, and the variance between groups may be related to the nature of the pathogens.

\section{Acknowledgements}

We would like to convey our thanks to the College of Veterinary Medicine, University of Mosul, and to the workers in the Animal House for their support.

\section{Conflicts of interest}

The authors declare no conflict of interests with regard to the manuscript.

\section{References}

1. Mikaeel FB, Al-Saeed AT. Molecular detection and seroprevalence of Toxoplasmosis in free range local chickens (Gallus domesticus) in Duhok province, Iraq. Iraqi J Vet Sci. 2020;34(2):247-252. DOI: $10.33899 /$ ijvs.2019.125885.1173

2. Sakban FM, A'aiz N.N. Investigate the Toxoplasma gondii infection in the consumed beef in Al-Diwaniyah province. Iraqi $\mathrm{J}$ Vet Sci. 2020;34(2):95-99. DOI: 10.33899/ijvs.2020.164336

3. Kim H, Kim Y, Kang S, Lee H, Rhie H, Ahn H, Lee S. Prevalence of Toxoplasma gondii in stray cats of Gyonggi-do, Korea. Korean J Parasitol. 2008;46(3):199-201. DOI: 10.3347/kjp.2008.46.3.199

4. Taylor MA, Coop RL, Well RL. Veterinary parasitology. $4^{\text {th }}$ ed. Chichester: Wiley Blackwell; 2016. 144-145 p.

5. Hill D, Dubey JP. Toxoplasma gondii, transmission, diagnosis and prevention. Clin Microbiol Infect. 2002;8(10):634-640. DOI: 10.1046/j.1469-0691.2002.00485.x

6. Montoya JG, Remington JS. Management of Toxoplasma gondii infection during pregnancy. Lin Infect Dis. 2008;47(4):554-566. DOI: $10.1086 / 590149$

7. Mikaeel FB, Al-Saeed AT. Molecular detection and seroprevalence of toxoplasmosis in free range local chickens (Gallus domesticus) in Duhok province, Iraq. Iraqi J Vet Sci. 2020;34(2):247-252. DOI: $\underline{10.33899 / i j v s .2019 .125885 .1173}$
8. Abu-Dalbou M, Ababneh M, Giadinis N, Lafis L. Ovine and caprine toxoplasmosis (Toxoplasma gondii). IJVST. 2010;2(2):61-76. [available here]

9. Montoya JG, Leisenfeld O. Toxoplasmosis. Lancet. 2004;363:19651976. DOI: $10.1016 / \mathrm{S} 0140-6736(04) 16412-\mathrm{X}$

10. Weiss LM, Dubey JP. Toxoplasmosis: A history of clinical observations. Int J Parasitol. 2009;39(8):895-901. DOI: 10.1016/j.ijpara.2009.02.004

11. Yang XF, Fan GY. Effect of cadmium exposure on the histopathology of cerebral cortex in juvenile mice. Biol Trace Elem Res. 2015;165(2):167-172. [available here]

12. Jaafar RS. Bioremediation of lead and cadmium and the strive role of Pediococcus pentosaceus probiotic Iraqi J Vet Sci. 2020;34(1):51-57 DOI: $10.33899 /$ ijvs.2019.125581.1092

13. Rees TJ. The toxicology of mate reproduction [master's thesis]. Port Smith: Port Smith University; 993. 186 p.

14. Sabolic I, Linbojevic M, Herkkramberger CM, Brown D. Cadmium metallothionine endocytosis of brush border transports in rat renal proximal tubules. Renal Physiol. 2002;283:1389-1402. DOI: 10.1152/ajprenal.00066.2002

15. Al-Derawi KH. Effects of cadmium chloride on some endocrine glands (thyroid and adrenal) in male rats (Rattus norvegicus). Iraqi J Vet Sci. 2018;32(2):211-217. DOI: 10.33899/ijvs.2019.153851

16. Health line. Cortisone, oral tablet. University of Illinois. 2018. [available at]

17. Soulsby EL. Helminths, arthropods, and protozoa of domesticated animals. $7^{\text {th }}$ ed. London: Bailliere; 1986. 680 p.

18. Dubai JP, Thalliez MD. Persistance of Toxoplasma gondii tissue cysts in edible tissues of cattle fed Toxoplasma gondii Oocysts. Am J Vet Res. 1993;54(2):270-273. [available here]

19. Luna, LG. Manual of histologic staining methods of the armed forces institute of pathology. $3^{\text {rd }}$ ed. New York: McGraw-Hill book company; 1968. 1-71 p.

20. Attarbashee RK, Abu-Raghif A. Comparative treatment of induced ulcerative colitis in male rat model by using cinnarizine and sulfasalazine. Iraqi J Vet Sci. 2020;34(2):465-472. DOI: $10.33899 /$ ijvs.2019.126170.1254

21. Ibrahim SM, Handool KO, Abdul AA, Abu J, Yusof SM, Ibrahimi M, Yusof LM. Histological evaluation of the possible role of $\mathrm{Na}+/ \mathrm{H}+$ entiporter and anion exchanger in endochondral ossification activities of secondary bone healing in rats. Iraqi J Vet Sci. 2020;34(2):465-472. DOI: $10.33899 /$ ijvs.2019.125832.1165

22. Alkhalidy KH, Alekealy KA, Almialy HM. Histopathological study of some internal organs in cats infected with Toxoplasma gondii. AlQadesyia J Vet Sci. 2014;13(2):11-15. DOI: 10.13140/RG.2.2.11928.03840

23. Al-Saidya AM, Al-Kennany ER. Pathological and histochemical study on cats and mice experimentally infected with Toxoplasma gondii. Iraqi J Vet Sci. 2006;20(2):249-263. DOI: 10.33899/ijvs.2006.45821

24. Al-Khanaq MN, Jasim GA. Study of histopathological changes in white male rats experimentally infected by Toxoplasma gondii. Al-Qadesyia J Vet Sci. 2015;14(2):6-11. [available here]

25. Wang B, Du Y. Cadmium and its neurotoxic effects. Oxidat Med Cellul Longevity. 2013;898034:1-12. DOI: 10.1155/2013/898034

26. Manton WI, Cook JD. High accuracy (stable isotope solution) measurements of lead in serum and cerebrospinal fluid. Brit J Indust Med.1984;41(3):313-319. [available here]

27. Kaoud HA, Mekawy MM. Effect of cadmium pollution on neuromorphology and function of brain in mice offspring. Nat Sci. 2011;9(4):28-35. [available here]

28. Afifi OK, Embaby AS. Histological study on the protective role of ascorbic acid on cadmium induced cerebral cortical neurotoxicity in adult male albino rats. Journal of microscopy and ultrastructure. 2016;4(1):36-45. DOI: 10. 1016/j.jmau.2015.10.001

29. Borges VC, Santos FW, Rocha JB, Nogueira CW. Heavy metals modulate glutamatergic system in human platelets. Neurochem Res. 2007;32(6):953-958. DOI: 10.1007/s11064-006-9231-7

30. Yuan $\mathrm{CY}$, Jiang $\mathrm{XH}, \mathrm{Xu} \mathrm{XH}$. Cadmium-induced apoptosis in primary rat cerebral cortical neurons culture is mediated by a calcium signaling pathway. PLoS One. 2013;8:1-4. Doi: 10.1371/journal.pone.0064330 


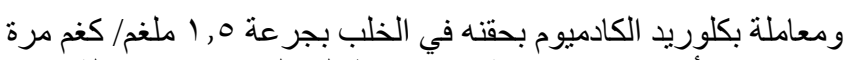

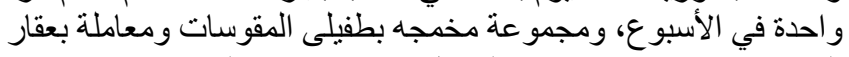

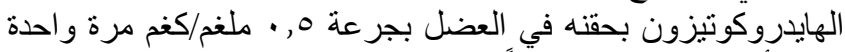

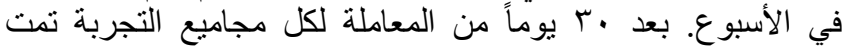

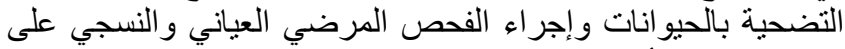

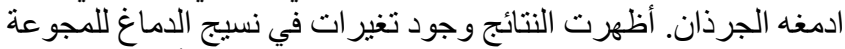

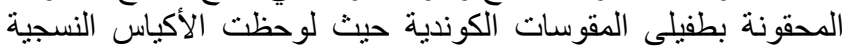

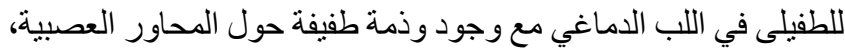
بينما كانت هنالك تغير ات إضمافية للمجمو عة المعاملة بكلوريد الكيات الكادميوم

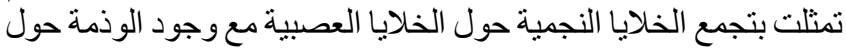

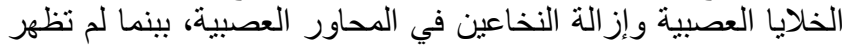

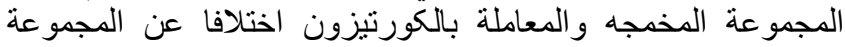

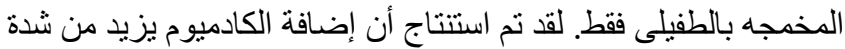

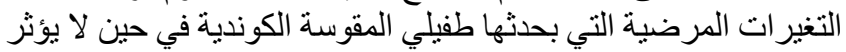

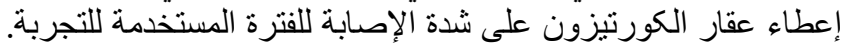

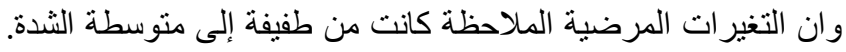

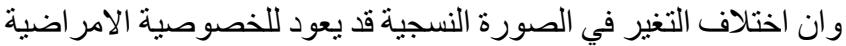

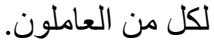

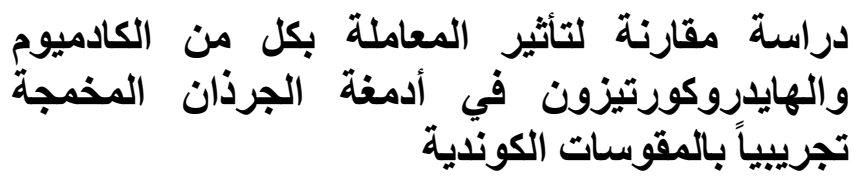

كرم هاثم الملاح'، سرى سالم أغوان` و قيس طالب العبيديץ

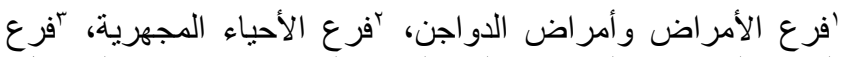

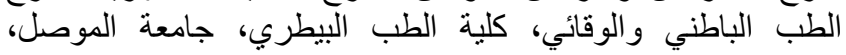

الموصل، العراق

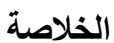

لمعرفة تأثر كل من كلوريد الكادميوم والكورتيزون على الخمج

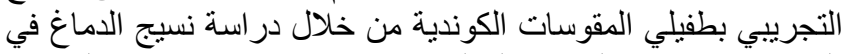

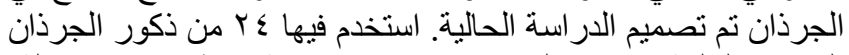

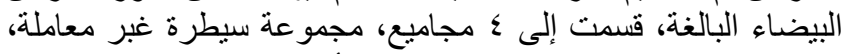

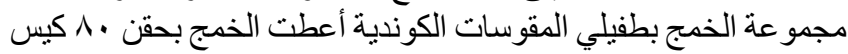
نسجي في الخلب لكل حيوان، ومجموعة مخمجه بطفيلي المقوسات 